\title{
Framework for Location Based Attendance System by Using Fourth Industrial Revolution (4IR) Technologies
}

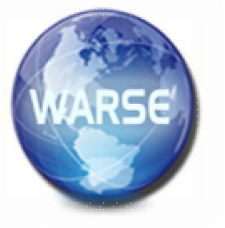

\author{
Azhar Ali ${ }^{1}$, Muhammad Yaqoob Koondhar ${ }^{2}$, Mansoor Hyder Depar ${ }^{2}, Z_{\text {Zulfikar Ahmed Maher }}^{2}$, \\ Muhammad Malook Rind ${ }^{3}$, Asadullah Shah ${ }^{4}$ \\ ${ }^{1}$ Virtual University of Pakistan, azharkhaskheli@gmail.com \\ ${ }^{2}$ Sindh Agriculture University Tandojam, Pakistan, Email yaqoobkoondhar@sau.edu.pk, \\ mansoor.hyder@sau.edu.pk, zamaher@sau.edu.pk \\ ${ }^{3}$ Sindh Madressatul Islam University, Pakistan, Email engineermalook@gmail.com \\ ${ }^{4}$ International Islamic University Malaysia , Pakistan, Email asadullah@iium.edu.pk
}

\section{ABSTRACT}

Information Technology (IT) is an emerging field that plays a significant role in every field of today's world. In the education systems, IT has replaced many traditional methods with trending digital technologies and solved the problems and hurdles that usually occur. Besides these, IT is a key factor that is responsible for digitization and automation that ultimately have led us to the $4^{\text {th }}$ industrial revolution (4IR), which is an upgrade of the previous 3 industrial revolutions. The 4IR is not only for industrial production, but it is also involved in almost every field including education and commercial domains. In every organization, including an educational institute or any other commercial organization, attendance has a great importance. In the recent past, several IT technologies have been used to replace the traditional paper-based attendance method with digital attendance mode, for that purpose, there have been several techniques in use since long time i.e. Near Field Communication; NFC, Radio Frequency Identification; RFID, Biometric, Quick Response Code; QR-Code, etc. Though, these types of techniques were very efficient but had some flaws such as risks of prone attendance, the queue of a crowd waiting in front of attendance device, high time consuming etc. This research was planned to overcome these issues by introducing a new approach by designing a framework for location-based attendance system using digital technologies of the 4IR. The designed framework was based on BYOD (Bring Your Own Device) trend, in which students rather than teachers can mark their attendance using their own devices. This framework was a 3 layered framework i.e. client layer, data synchronization layer, and server layer. The framework was validated by developing a system and testing it at the Information Technology Centre, Sindh Agriculture University Tandojam, Pakistan. For calculating the empirical results, an evaluation was performed. The designed framework proved to be more secure, all the data in the framework was encrypted with a strong encryption algorithm, final attendance of successful students was stored in the blockchain structure to maintain the confidentiality and integrity in data. The designed framework used triple authentication i.e. biometric authentication, QR-code authentication, and location based authentication that reduced the risk of prone attendance.

Key words: 4IR, Attendance, Artificial Intelligence, Blockchain.

\section{INTRODUCTION}

Information Technology (IT) is an emerging field that plays a significant role in today's world. It is involved in almost every field such as medical science, engineering, agriculture, transportation, education etc. [1]. Human lives have become easier and comfortable because of the emerging technologies of IT specifically Internet of Things (IoT), Artificial Intelligence (AI), Cloud Computing and Blockchain [2]. Besides all, IT is a key factor that is responsible for the rise of the $3^{\text {rd }}$ and $4^{\text {th }}$ Industrial Revolutions [3]. 4IR is an upgradation of the previous 3 revolutions, as the $1^{\text {st }}$ revolution started in Britain, which introduced hydraulic and steam powered machines in the factories to facilitate the humans to be more productive, the $2^{\text {nd }}$ revolution began in the United States which emerged with mass production and electrical energy and took the people to affordable consumer products of mass production and the $3^{\text {rd }}$ revolution emerged with IT and electronic products to enable the efficient and automated manufacturing processes [3]. 4IR is characterized by different digital technologies such as AI, cloud computing, IoT, blockchain, and other technologies [4]. Blockchain technology enables us, to store the data in a secure manner and incorporates the integrity in the data [3], simultaneously clouds have made data storage easier and provided lot of space. In addition, IoT has connected the whole world together with devices and sensors and made it as digital globe [5]. While the AI has made the processing of big data easier and made devices and software, smart and intelligent [6]. The 4IR is not only for industrial productions; however, it is also concerned in all fields including engineering, manufacturing, natural science, education etc. [3]. 
The attendance is one of the most important activities of every organization and employer. [7]. In education systems, several policies are set by the higher education commission, to be achieved [8]. In commercial organizations, most of the employees are paid based on attendance recorded by the employer [9]. In these days, to record attendance, there are many techniques applied in different organizations [10]. In the earlier days, paperwork has been in practice to take the attendance of the students and employees at educational institutes and organizations. In the paper-based attendance, number of methods were applied to record the attendance including, calling the name of each student or employee, passing the piece of paper to all the students or employees etc. [11] However, such practices were much laborious and time-consuming [12]. The paper-based attendance was also considered to be less secure because there were many chances of prone attendances, especially, when the paper was passed to other students, they could mark the attendance of absent students or could mark the prone attendances as well [13]. In the recent past, several IT technologies have been used to replace the traditional paper-based mode of attendance [14], such as Near Field Communication; NFC [15], Radio Frequency Identification; RFID [16], Biometrics [17], Quick Response Code; QR-Code [18], etc. These digital systems can be categorized in two groups, one is centralized, while other one is distributed or dedicated. The centralized system included a central computer/device/reader, which was used to detect the students/employees and marking the attendance of a particular attendee. Though, this type of technique was very efficient; however, they were causing the crowding of students/employees in the queues. For example, fingerprint-based biometric attendance system was in common practice but was found less suitable due to crowding concerns and high time consumption. In fingerprint-based biometric attendance system, an average of 3 seconds were consumed to record the attendance of one student, while for noting the 200 attendees, 10 minutes were wasted for getting the attendance [19].

Furthermore, to address these issues, distributed/dedicated systems were introduced. These systems were mostly based on BYOD (Bring Your Own Device) trend, in which students rather than teachers can mark their attendance using their device. These types of systems had some flaws, such as there was the risk of prone attendance [20] as one can give his/her mobile to a friend to mark the attendance. Besides prone attendance, if someone has a low-quality camera mobile, and the classroom is larger in length, he/she may get difficulty in scanning the displayed QR code [21].

\section{RELATED WORK}

[22] proposed an attendance system based on barcode technology. In their proposed system barcode was attached on the back of students' ID cards which contained information about the students such as department, faculty, year, etc. When the student entered the classroom, he/she was just required to swipe the card in the barcode reader and attendance would be recorded. This system supposed to be accurate since the time of attendance was also recorded. [23] designed a wireless-based barcode attendance system. This system worked like other barcode systems but with this system, a smart mobile application was developed to read the barcode of students rather than the barcode reader device. All the teachers and professors were required to install the application in their mobile application and then scan the bar code of students. Once the barcode was scanned, it sent the message to another terminal of the system that was a desktop application that validated the students and stored the attendance with student's data into a database to make it secure. This system also provided the capability of downloading the report of attendance in Excel format for summarizing or further operations.

[24] described an automatic RFID based attendance system that can be used for professional gatherings, conferences, training, etc. Rooms were embedded with RFID readers and once the attendees entered the classroom, his/her attendance was stored in the databases. [16] proposed an attendance management system based on the RFID with Arduino and a web-based application. This system was used to record the presence and absence of students. In their system RFID reader related to an Arduino microcontroller which could send the signal to the server via using a wired or wireless medium. To manage the attendance a web-based application was developed by using the WAMPP server, PHP, and MySQL. Attendance was stored in the MySQL database. This proposed system was also able to display the information to students as well. [25] suggested a QR code-based attendance system but in this system, student scanned the QR Code himself rather than the professor, which was displayed at the beginning of the presentation, when the professor allowed latecomers then the QR Code was attached at every slide of the presentation in the corners. [26] developed a web-based and QR code-based attendance system that provided data security and was also easy to use. At the beginning of each course, to confirm their attendance, users (professors and students) were required to scan their unique $\mathrm{QR}$ code, assigned to them, during or at the beginning of each lecture, using QR reading devices within the classrooms. Based on this, the lecture and student attendance record and other necessary data were recorded.

[27] developed a facial recognition-based method to take attendance of students and employee attendance, this system included three applications for students, parents, and teachers to use and manage application. This system was based on Euclidean distance which was calculated by Eigen Faces, Fisher Faces, and Local binary faces techniques of facial 
recognition. Another biometric system was developed using Raspberry Pi based on fingerprint by [28], because the fingerprint is the most accurate and authentic biometric. In their developed system, the fingerprint of students was saved in the system which was then matched with students on the time of attendance, on the successful match attendance was sent to the server using WiFi and saved in the database while displaying a success message in the LCD.

A system for location recognition and prediction was proposed by [29] using a smartphone environment. This system could recognize the location and predicting the destination of the user. It recognized user location by combining $\mathrm{k}$ nearest neighbor and decision trees and predicted user destination using hidden Markov models.

[30] proposed deep learning and facial recognition-based system with controlling the door access. This system was based on the Raspberry Pi camera and Raspbian OS which was installed on the SD card. A camera and screen related to the Raspberry PI controller, students were just required to place the face in Infront of the camera, and the camera captured the picture which was then sent to the controller. The controller was a programmer with a facial recognition algorithm i.e. Local Binary Pattern algorithm and compares the student's image with a trained dataset image and opened the door if authenticated and stored attendance in databases. The system had $95 \%$ accuracy with the dataset of 11 person images. [31] addressed an approach for an accurate attendance system based on a deep learning algorithm. This system kept the track of students' entry and exit. When the student entered an institute or university, the system detected the face and stored the data into the database, and when the student exited from the institute or university, exit time was stored, while maintaining the total time of the lecture, etc.

\section{DESIGNED FRAMEWORK}

The designed framework consisted of 3 layers, client layer, server layer and data synchronization layer that was an intermediatory layer between client layer and server layer whose responsibility was to exchange and synchronize the data between these layers, it could also be renowned as a channel between client and server. This 3-layered framework was designed (Figure 1) while keeping in consideration the digital technologies of the $4^{\text {th }}$ industrial revolution (4IR) such as Artificial Intelligence (AI), Blockchain, Cloud Computing, Internet of Things (IoT), and other contactless technologies including Quick Response Code (QR-Code) and biometric etc. Figure 1. shows the designed framework developed in current study.

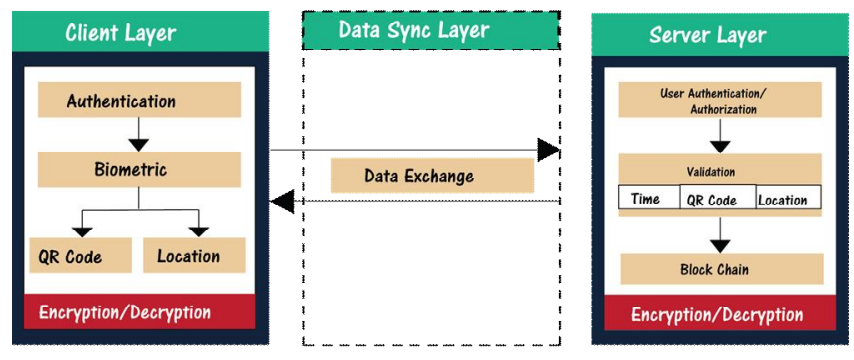

Figure 1: The designed framework for location-based attendance system developed in current study.

The client layer was for the attendees, who work in the organizations or the students at educational institutes. This layer involved tripe authentications i.e. biometric authentication, QR code authentication and location based authentication. Attendee was authenticated to login by password credentials and then again by using biometric authentication. After the biometric, this layer made use of Quick Response code to request the server for authentication and recording attendance, that request was sent by scanning the QR code of attendee which was embedded in his/her ID card. The request contained, request information with detail of attendee and QR code, time of scanning the QR code and coordinates (latitude and longitude) of the location of attendee. The coordinates were collected by using the Geographic Position Service (GPS). All the data of the client layer, data of request sent, and response received from server, is encrypted with a strong encryption algorithm to maintain the confidentiality and integrity in data. To implement this layer, a system was designed, in which a camera sensor was used to detect and capture the face of attendees and QR code while GPS device/module for the location, in any microprocessor/microcontroller such as Raspberry PI, Arduino Uno etc. Since camera and GPS sensors were already built-in today's smartphone, though smartphone was utilized for this layer.

Data synchronization layer was an intermediatory layer between the client and server layer. This layer was responsible for exchanging the information and communication between client layer and server layer. For this layer, any wired or wireless channel was used; however, cloud was more appropriate.

Server layer acts as a server in the designed framework. This was basically for teachers or administrators who manages the attendance, this layer was made automated or manual as well. The responsibility of this layer was to validate the request sent by the client and take appropriate decisions based on the data. This layer used AI algorithms to process the data, Blockchain structure to store the data. At the first, this layer decrypts the request sent by client layer and validated it based on the criteria defined. The criteria were consisted of: 
- The range of area (latitude and longitude of different corners of the classroom/place)

- The timing of the classroom/session (start time and end time)

- Any educational institute, like department of university, has several batches enrolled, therefore attendees' QR codes were designed based on the categories of batches. Thus, QR code category is also defined in the criteria.

At first, this layer validated the time at which request was sent by client with the time defined in the criteria and then it validated the QR code category and in the last, it validated the location of attendees. When the data was successfully validated, attendance was recorded and stored in the blockchain structure to maintain the data integrity. The data stored in the blockchain was encrypted to achieve the confidentiality of data. For this layer, the system was developed and hosted on the clouds etc.

\section{METHODLOGY}

To validate the designed framework, a system was developed. For each of layer different applications was developed and for data synchronization layer cloud was made in use. The empirical results were calculated though a pilot study, in which an evaluation was performed at Sindh Agriculture University Tandojam.

In the developed system, first of all the criteria was defined by using server application i.e. desktop application. For that purpose, server-side application was logged in with registered credentials and home page was opened. It had a dashboard, containing all the links to other interfaces/pages/activities of system. A criterion was defined in the server application, for which, different batches and courses were added in using manage courses batches and manage courses pages, respectively. Since the designed framework uses location of attendee to validate the attendance. A form was also provided to define the range of classroom, different corners i.e. north east corner, north west Corner, south east corner, south west corner. 1 classroom ranges were defined. Below figure shows all the steps followed by teachers to define the criteria in the server application.

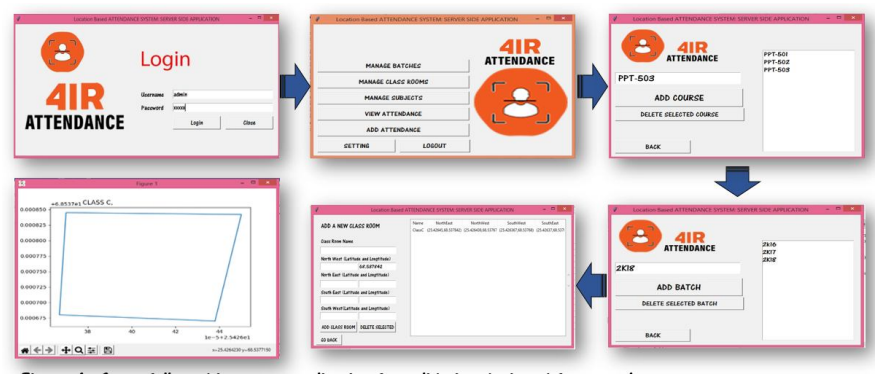

Figure 2: Screenshots of steps followed by teacher in server application during the evaluation.
After the criteria defined in the server application, students were asked to record their attendance. They signed their selves up by entering the data in form provided in client application. After the students signed up, they logged in with their authentic credentials. After logging in, students were required to place the face Infront of camera, so that application could detect and recognize the face to authenticate and authorize the students. The reason behind using double authentication here was to secure the system. The home page had also a navigation drawer, from which users could jump to other activities/fragments of the client application. The attendees were also notified, whether their attendance is recorded or not, in home activity of the client application.

Once the class timing started, students were asked to scan the $\mathrm{QR}$ code using their smart applications. After $\mathrm{QR}$ code scanned, request was sent to cloud, in the real time database which was then downloaded in the server application. Following figure shows all the steps followed by students in the client application during the evaluation.

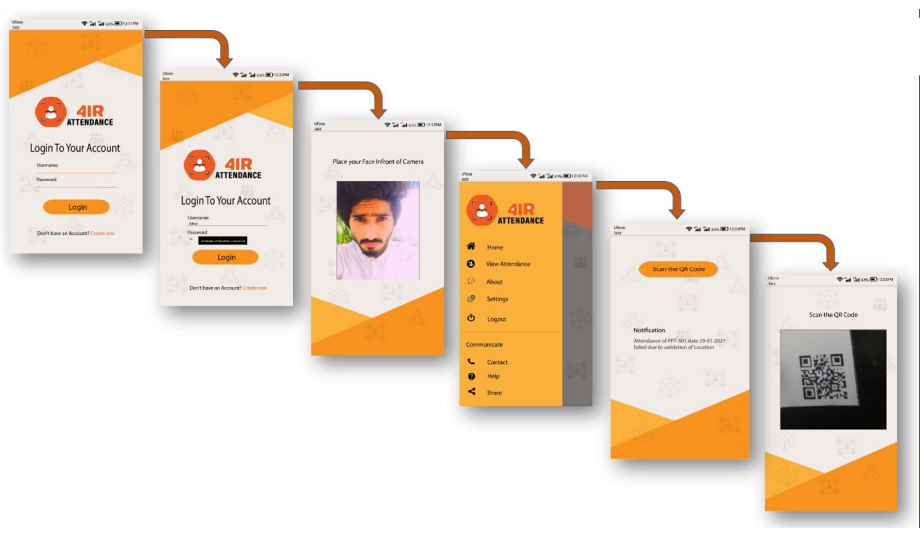

Figure 3: Screenshots of steps followed by students in client application during the evaluation.

The submitting author is responsible for obtaining agreement of all coauthors and any consent required from sponsors before submitting a paper. It is the obligation of the authors to cite relevant prior work.

\section{RESULTS}

The evaluation was performed at the Sindh Agriculture University Tandojam which was comprised of 115 participants The 5 groups were formed from total of 115 participants and criteria was defined in the server application The different groups divided during the evaluation of 4IR attendance system are presented in Figure 4.9. Among 115 students, 95 students were sitting inside the classroom range, while the remaining 12 were outside the classroom range. The total of 8 students were asked to come late to classroom, probably after 15 minutes. The 8 students were provided the smart mobiles of other students to sit in the class on behalf of them. While 15 students were provided with unauthentic ID cards (Figure 4). 


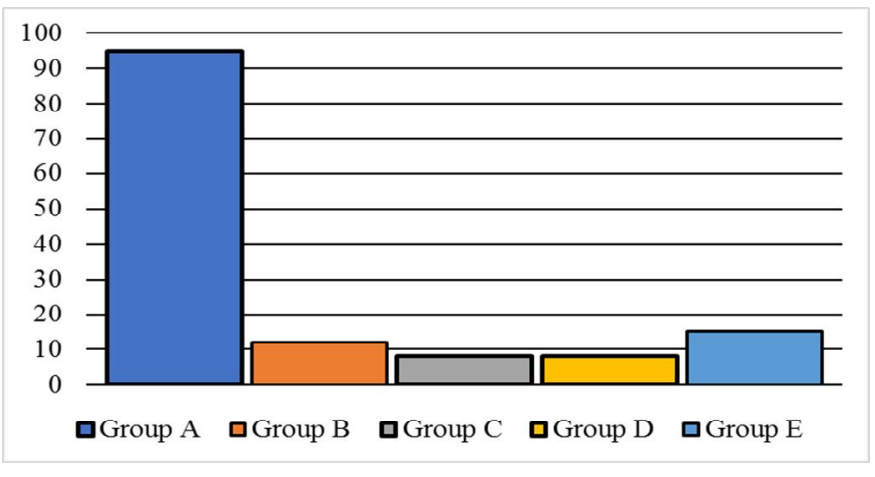

Figure 4: The students divided into different groups during evaluation process of 4 IR system.

The scatter plot of evaluation consists of blue line which represents the boundary line of the classroom and the area between the blue line shows the classroom area. The small colorful scatters in the plot show the number of students. Since there was a total of 115 participants, but only 107 scatters were plotted because the remaining 8 students were failed in the biometric authentication, therefore, their request could not be sent to the server application, thereafter they were not marked in the plot. Among 107 students, the total of 95 were scattered within the classroom range and the remaining 12 were detected outside the classroom range. However, the students whose QR validation was failed and others who came late in the classroom were also detected in the scatter plot because their request was sent to the server, but it was failed in validation and marked as absent (Figure $5)$.

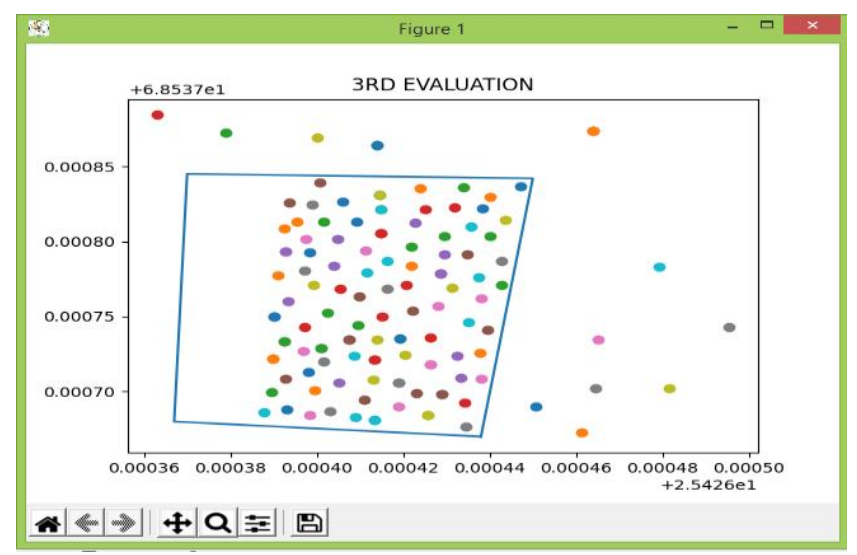

Figure 5: The scatter plot representing the students and boundary line during the evaluation in 4IR system.

Since 115 students were participating and 12 of them were detected outside the classroom range and observed as absent during the evaluation of 4IR attendance system. Among the remaining 95 students who were sitting inside the classroom range 8 students came late in the class which were marked as absent because of the criteria defined in the server application of 4IR attendance system. Moreover, the 15 students' QR code authentication was failed and recorded as absent in the classroom attendance. Since 8 students of Group D were sitting on behalf of other students, while having smart mobiles of other registered students, they were failed in biometric recognition by the system specially and marked as absent. Though 64 students were recorded as present and the remaining 51 were as absent. (Figure 6).

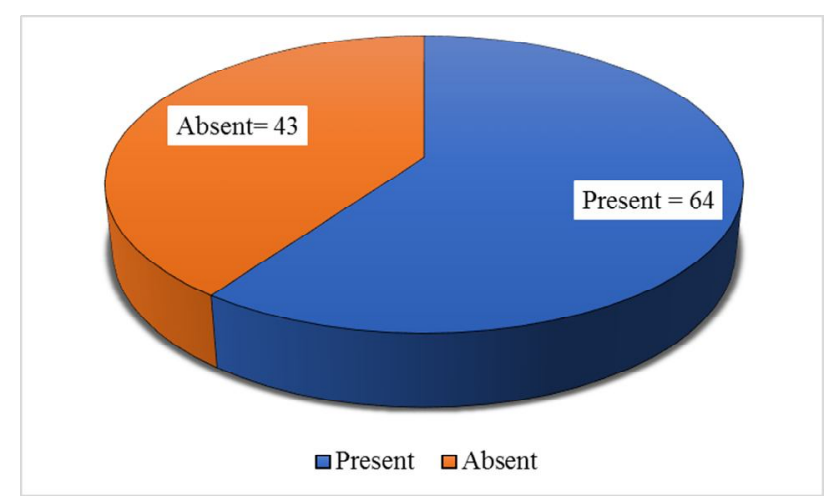

Figure 6: The ratio of presence and absence of students in evaluation of 4IR system.

The stored attendance data of students in the blockchain structure shown in Figure 8. The total of 64 students were recorded as presents, therefore, 65 blocks were created and chained with one, then with another stepwise. First block of the chain was genesis block which is always created and placed at the first position of the blockchain (Figure 7).

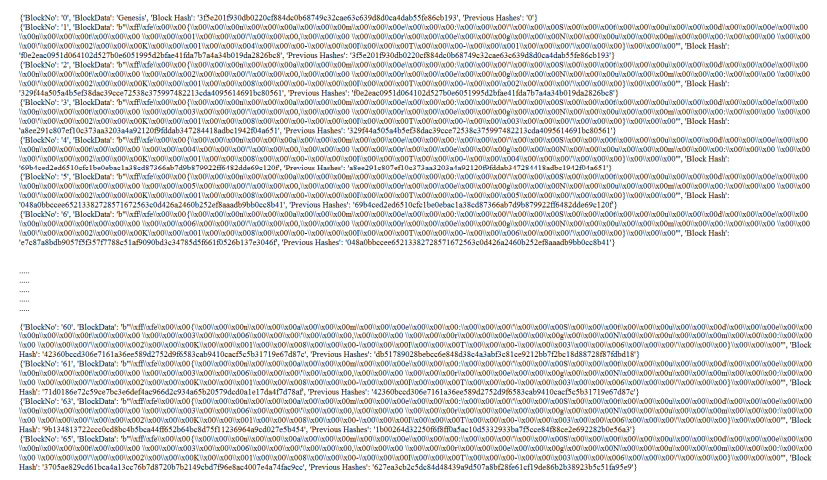

Figure 7: The data stored in the blockchain structure during the evaluation in 4IR system.

\section{CONCLUSION}

Digitization and automation have led us to the $4^{\text {th }}$ industrial revolution. In the current study, 4IR technologies incorporated into attendance systems, in which a three-layered framework was designed that made use of $\mathrm{QR}$ code and biometric for authentication. Whereas the location-based information was used to validate and record the attendance. This framework reduced the maximum possible risk of prone attendance. 
To keep the data confidential and secure, all the data was encrypted with a strong encryption algorithm; while to keep integrity in data it was stored in the chain type structure (Blockchain Structure). Three evaluations validated the designed framework: The empirical results showed successful; 1) validation of students' location with accuracy; 2) validation of time criteria and 3) detected the prone attendance by validating the $\mathrm{QR}$ code and biometric. It was observed much-secured solution for recording attendance especially in the educational institutions and commercial organizations. Since the framework was based on BYOD trend, thus, it was proved to be cost-effective, and user-friendly.

\section{REFERENCES}

1. S Bernacki, M. L., Greene, J. A., \& Crompton, H. (2020). Mobile technology, learning, and achievement: Advances in understanding and measuring the role of mobile technology in education. Contemporary Educational Psychology, 60, 101827.

2. Meng, G., \& Saddeh, H. (2020). Applications of Machine Learning and Soft Computing Techniques in Real World. International Journal of Computer Applications \& Information Technology, 12(1), 298-302.

3. Xu, M., David, J. M., \& Kim, S. H. (2018). The fourth industrial revolution: Opportunities and challenges. International journal of financial research, 9(2), 90-95.

4. Shu, Z. (2014). The Industry 4.0 and intelligent manufacturing. Machine Design and Manufacturing Engineering, 43(8), 1-5.

5. Karabegović, I. (2018). The Role Of Industrial And Service Robots In The 4th Industrial Revolution-" Industry 4.0". Acta Technica Corviniensis-Bulletin of Engineering, 11(2), 11-16.

6. Oke, A., \& Fernandes, F. A. P. (2020). Innovations in teaching and learning: Exploring the perceptions of the education sector on the 4th industrial revolution (4IR). Journal of Open Innovation: Technology, Market, and Complexity, 6(2), 31.

7. Yang, H., \& Han, X. (2020). Face Recognition Attendance System Based on Real-Time Video Processing. IEEE Access, 8, 159143-159150.

8. Qureshi, J. (2017). Impact Of HEC Employment Initiatives On Teachers' performance In Public Sector Universities of Pakistan (Doctoral dissertation).

9. Simbolon, A., \& Puteri, I. (2015). Attendance Challenge Peer to Peer Lending Economic Development in Indonesia. Law Review, 50(643).

10. Vinod, V. M., Thokaiandal, S., Sindhuja, C. S., Mekala, V., Manimegalai, M., \& Prabhuram, N. (2020). A Comprehensive Study On Academic And Industry Authentication And Attendance Systems. International Journal of Scientific \& Technology Research, 9(3).
11. Myint, K. S., \& Nyein, C. M. M. (2018). Fingerprint based attendance system using arduino. International Journal of Scientific and Research Publications, 8(7), 422-426.

12. Geetha, P. (2020). Virtual Attendance Monitoring System For G-Suite Accounts. Solid State Technology, 702-711.

13. Simbolon, A., \& Puteri, I. (2015). Attendance Challenge Peer to Peer Lending Economic Development in Indonesia. Law Review, 50(643).

14. Nivetha, R., Kavipriya, M., Pavithra, R., Jeyanthi, C., \& Lakshmi, V. S. (2020). Student Attendance System Using RFID. International Journal of Research in Engineering, Science and Management, 3(10), 16-19.

15. Mohandes, M. A. (2017). Class attendance management system using NFC mobile devices. Intelligent Automation \& Soft Computing, 23(2), 251-259.

16. Rjeib, H. D., Ali, N. S., Al Farawn, A., Al-Sadawi, B., \& Alsharqi, H. (2018). Attendance and information system using RFID and web-based application for academic sector. International Journal of Advanced Computer Science and Applications, 9(1).

17. Devikar, P., Krishnamoorthy, A., Bhanage, A., \& Chauhan, M. S. (2016). IoT based biometric attendance system. Mumbai University: India. No Sensor Nilai OPC Alarm, 1.

18. Wei, X., Manori, A., Devnath, N., Pasi, N., \& Kumar, V. (2018). QR Code Based Smart Attendance System. no. October.

19. Sharanya, T., Sucharith, P., Kasturi, U., \& Mahesh, T. (2020). Online Attendance using Facial Recognition. Int. J. Eng. Res, 9(06), 202-207.

20. Shah, D. Quick Response (QR) Code based Attendance Marking System. International Journal of Computer Applications, 975, 8887.

21. Maier, D., Erb, H., Mullan, P., \& Haupert, V. (2020). Camera Fingerprinting Authentication Revisited. In 23rd International Symposium on Research in Attacks, Intrusions and Defenses (\{RAID $\}$ 2020) (pp. 31-46).

22. Saheed, Y. K., Hambali, M. A., Adeniji, I. A., \& Kadri, A. F. (2017). Fingerprint based approach for examination clearance in higher institutions. FUOYE Journal of Engineering and Technology, 2(1), 47-50.

23. Ong, E. T. (2017). Wireless Barcode-based Attendance Taking System (Doctoral dissertation, Tunku Abdul Rahman University College).

24. Nguyen, H. K., \& Chew, M. T. (2017, February). RFID-based attendance management system. In 2017 2nd Workshop on Recent Trends in Telecommunications Research (RTTR) (pp. 1-6). IEEE.

25. Masalha, F., \& Hirzallah, N. (2014). A students attendance system using $Q R$ code. International Journal of Advanced Computer Science and Applications, 5(3), 75-79. 
26. Nuhi, A., Memeti, A., Imeri, F., \& Cico, B. (2020, June). Smart attendance system using $\mathbf{q r}$ code. In 2020 9th Mediterranean Conference on Embedded Computing (MECO) (pp. 1-4). IEEE.

27. Samet, R., \& Tanriverdi, M. (2017, September). Face recognition-based mobile automatic classroom attendance management system. In 2017 International conference on cyberworlds (CW) (pp. 253-256). IEEE.

28. Sawant, R., Talekar, M., Salvi, N., Shetye, R., \& Chavan, V. (2019). Portable Biometric Attendance System using Raspberry Pi.

29. Cho, S. B. (2016). Exploiting machine learning techniques for location recognition and prediction with smartphone logs. Neurocomputing, 176, 98-106.

30. Salim, O. A. R., Olanrewaju, R. F., \& Balogun, W. A. (2018, September). Class attendance management system using face recognition. In 2018 7th International conference on computer and communication engineering (ICCCE) (pp. 93-98). IEEE.[31] Haldar, R., Chatterjee, R., Sanyal, D. K., \& Mallick, P. K. (2019). Deep learning based smart attendance monitoring system. In Proceedings of the Global AI Congress. 